\title{
Actionable equality
}

In the past decade, many challenges faced by women seeking to advance their scientific careers have been
identified. Although new policies encouraging equal opportunities in academic research are closing the gap,
multipronged measures are needed in order to achieve long-lasting changes that make science gender-blind.

M edical and technological progress across all disciplines has resulted from the work of talented women scientists throughout history. However, a discriminatory culture in which men take an outsized amount of credit has often relegated the merit of these women to the background, thereby perpetuating an unequal gender representation that still persists today in most areas of scientific research.

Changes in educational policies have resulted in significant advances towards closing the gender gap. In the United States, more than $60 \%$ of bachelor's and master's degrees are now earned by women ${ }^{1}$.

In scientific research, the underrepresentation of female researchers among faculty is a well-documented systemic problem. According to the most recent edition of the UNESCO Science Report $^{2}$, nowadays women earn about half of the PhDs in sciences and health worldwide; however, the gender gap starts once women graduate and peaks at the faculty level. For example, in the European Union, in only 1 in 5 countries are at least $45-50 \%$ of professors women, and as few as $11 \%$ of senior-level faculty positions are occupied by women ${ }^{3}$. Gender bias and institutional barriers, including those related to pregnancy and childcare, have imposed a greater burden for women in science than their male counterparts. They also receive lower salaries on average ${ }^{4}$ and obtain lower start-up funding packages than their male peers 5 . Inevitably, this has a detrimental effect on the number and impact of publications with women as senior authors ${ }^{6}$, which results in fewer opportunities to progress towards leadership positions.

A recent analysis of cancer research investment in the United Kingdom ${ }^{7}$ shows that over $75 \%$ of funds were allocated to male investigators during 2000-2013. Similarly, recent reports in scholarly publishing have revealed that, despite the picture being obscured by limited collection of demographic data, women are less often invited to peer-review and to author invited articles $^{8}$. Although these differences might be explained in part by a lower number of women reaching senior scientist positions, they exemplify the existing gender gap that has historically affected academic research despite a long-standing awareness of the problem.

Specific recommendations and policies put in place in recent years seem to be having an impact in combating this trend. The Athena SWAN (Scientific Women's Academic Network) Charter was created in 2005 in the United Kingdom as a framework to encourage academic centers to advance gender equality. This program establishes a scoring system-ranging from bronze to silver to gold-that grades the commitment of medical science departments and their creditable impact in implementing explicit actions toward achieving gender equality. The Athena SWAN grading system lacked proceedings for compliance when it was launched; however, in 2011 the National Institute for Health Research-one of United Kingdom's major funders of applied biomedical research-announced that only applicants with a silver or higher rating would be considered for receiving funding from the agency. This announcement encouraged wide participation of medical departments in this program and was perceived to have a positive impact in advancing gender equality ${ }^{9}$. Echoing this initiative, the New York Stem Cell Foundation Initiative on Women in Science and Engineering (IWISE) short-listed specific actionable strategies, including an institutional report card to quantify gender balance in grant applicants, to ensure that women remain, compete, and thrive in their scientific careers ${ }^{10}$. These are certainly steps towards breaking the glass ceilings that have-and continue to-deter women from accessing the same opportunities as men; however, enforcement measures will be required to ensure compliance.

In scientific publishing, the editors also have a role to play. At Nature Medicine, we are conscious of the need to mitigate the disparities in gender participation in peer review and publication and are consequently pursuing a greater involvement of women scientists in review activities and authorship of commissioned content. Follow-up analyses of longitudinally collected data will determine the real impact of these initiatives over time.
Beyond these measures, further work is necessary to achieve a widespread shift in culture and societal thought whereby women are no longer considered less qualified, less capable and less deserving than men. Outreach activities, role models and mentors are needed to inspire and provide advice to women scientists at different career stages; gender-focused educational programs targeting often unconscious gender biases at research institutions can help in mitigating prejudiced behaviors; and the establishment of specific award programs by grant-making organizations to avoid interruptions in the work of women scientists during the most productive years of their careers will create more space for equality. Lastly, an effort toward transparency, data collection and accountability is essential to have measurable outcomes that determine the efficacy and sustainability of these initiatives. There is a long way towards achieving stable gender equality in scientific research. Equal representation of transgender scientists and minorities in the life sciences is also lagging. Long-lasting solutions will therefore require measures that ensure equal opportunities to all scientists throughout their careers and avoid a waste of talent that is detrimental to us all.

Published online: 9 July 2018

https://doi.org/10.1038/s41591-018-0118-3

\section{References}

1. White House Council on Women and Girls. Women in America: indicators of social and economic well-being http://digitalcommons.ilr.cornell.edu/key_workplace/799 (Washington, DC, 2011).

2. UNESCO. UNESCO Science Report: towards 2030 http://unesdoc.unesco.org/images/0023/002354/235406e.pdf (UNESCO Publishing, Paris, 2015).

3. European Commission. She figures 2012: gender in research and innovation (report. no. EUR 25617) (Publications Office of the European Union, Luxembourg, 2013).

4. National Science Foundation, National Center for Science and Engineering Statistics. Doctorate recipients from U.S. universities: 2016 (report no. NSF 18-304) (Alexandria, VA, USA, 2018).

5. Sege, R., Nykiel-Bub, L. \& Selk, S. JAMA 314, 1175-1177 (2015).

6. Sekhar, A. Nature 555, 165 (2018)

7. Zhou, C. D. et al. BMJ Open 8, e018625 (2018).

8. Ross, E. Nature https://doi.org/10.1038/nature.2017.21685 (2017).

9. Ovseiko, P. V. et al. Health Res. Policy Syst. 15, 12 (2017).

10. Smith, K. A. et al. Cell Stem Cell 16, 221-224 (2015). 